\title{
How Information Propagation in Social Networks Can Improve Energy Savings Based on Time of Use Tariff
}

\author{
Uduakobong E. Ekpenyonga,*, Jiangfeng Zhang ${ }^{\mathrm{b}}$, Xiaohua Xia ${ }^{\mathrm{a}}$ \\ ${ }^{a}$ Centre of New Energy Systems, Department of Electrical, Electronic and Computer \\ Engineering, University of Pretoria, South Africa \\ ${ }^{b}$ Department of Electronic and Electrical Engineering, \\ University of Strathclyde, United Kingdom
}

\begin{abstract}
The expected savings from energy efficiency projects are divided into two, direct savings and indirect savings. Direct savings refer to savings obtained through the personal effort of an individual implementing some energy efficiency measures. Indirect savings are achieved through information transmission of energy efficiency measures an individual has performed to his/her neighbour, this therefore can be associated as human contribution for energy savings through interactions in the social network. This paper formulates a mathematical model that calculates an expected energy cost savings model that consists of direct and indirect savings. Indirect savings are made through social interactions of people in a network over time. Direct savings are based on the Homeflex time of use tariff of South Africa. A case study of thirty-six households is used to illustrate the impact individuals have on the rest of their network in transferring information about the energy efficiency measures they have implemented. The results show that social interactions can
\end{abstract}

\footnotetext{
${ }^{*}$ Corresponding Author

Email address: uduak.ekpenyong@up.ac.za (Uduakobong E. Ekpenyong )
} 
improve energy efficiency savings and consequently reduce electricity cost. Keywords: Energy efficiency, Information entropy, Information distribution, Probability, Social network, Time of use tariff

\section{Introduction}

The importance of implementing energy efficiency measures that will reduce energy consumption is due to the high demand for electricity. Therefore, it is essential to know which people or households in a community to target that will spread information about energy efficiency measures to their neighbours and in doing so encourage their neighbours to reduce their electricity usage. Rewarding people for the effort they have made to reduce electricity consumption not only encourages them to continue applying their energy efficiency measures, but also enables them to tell their friends about their rewards. Human interaction increases the chances of energy efficiency in the residential sector at less cost to the utility company or government where the spread of information about energy efficiency is concerned. Therefore, propagation of information about energy efficiency measures among members of a social network can lead to a greater reduction in electricity usage within that network. This is because people are more likely to change to more efficient lifestyles because their friends or family has changed $\mathrm{Xu}$ et al. (2012), Peschiera et al. (2012), Jaina et al (2013), Chen et al (2012) and Wassaerman and Faust (1999).

Rewarding people for the information they have transmitted to their neighbours has been discussed in Ekpenyong et al (2014) and Ekpenyong et al (2013), using the expected power saving model. The expected power 
saving model consist of two components; the direct and indirect savings. The direct savings are referred to the energy cost savings directly measurable or observable and can often be determined by various measurement and verification techniques IPMV (2007). The indirect savings refer to the savings additional to direct savings which are achieved by social interaction of people in a network Ekpenyong et al (2014). In Ekpenyong et al (2014) the household with maximum expected power saving is identified using only the indirect saving because the direct saving is assume the same for every household. This paper continues the research on rewarding people for their effort in not just reducing electricity usage but also their influence that encourages other members of the in the community to reduce their electricity consumption. In Ekpenyong et al (2014), only the immediate power saved on an appliance is considered however, this paper takes the mathematical model further to include energy consumptions of households using the time-of-use tariff. This gives a clearer prediction when considering energy efficiency of the overall electricity usage of a household. The advantage to this paper is that the results obtained from the mathematical model, can be used to encourage people to save more energy when they are presented with their energy savings and that of their neighbours or the savings of the entire community at large. Although a similar study has been done by Chen et al (2012), Xu et al. (2012) and Jaina et al (2013) there has not been literature that uses information entropy to determine the influence of people with respect to energy efficiency savings.

In this paper, the expected energy saving model is formulated that determines the energy saved through direct and indirect savings over time, 
using the Homeflex time-of-use (TOU) tariff. The model depicts the real life situation where people in a community apply different types of energy efficiency measures and consequently save varying energy. Varying degrees of savings identifying people to target who will transmit information to the rest of their network depend not only on their personal efforts but also on their connections to their neighbours. Since people are not compensated for the information they provide to others when they propagate the usefulness of energy efficiency measures, this model continues the research of Ekpenyong et al (2014) to bridge that gap. This model is aimed at estimating the expected savings of people who encourage their neighbours to reduce their electricity usage through friendly interaction. When neighbours encourage one another to reduce their electricity consumption, it saves the utility company money on campaigns and advertisements.

Similar to the model in Ekpenyong et al (2014), the proposed model makes use of the knowledge of complex network Newman et al (2002), Watts and Strogatz (1998) and Milgram (1967) and information entropy Shannon (1948). One advantage of this proposed model is that it includes the reduction of the quality of information as time increases; this gives the duration the neighbours of a person with the energy efficiency information can free ride on that information. Free riders in energy efficiency are people who would have performed energy efficiency projects if they had the knowledge about the savings they could effect, even if no energy efficiency program was in place Weinstein et al (1989), Croucher (2011), King (1995). An individual who shares his success stories about energy efficiency measures to his neighbours, provide them with free information that they would have oth- 
erwise have had to spend some effort (either money or time) obtaining the information Croucher (2011). The free rider aspect of this model refers to the information received by neighbours when they adopt the actions of the person who undertakes an energy efficiency project. This human interaction is not always highlighted when the calculations of energy cost savings are performed; however it has a high impact on the success of energy efficiency projects.

A case study of thirty-six households is used to illustrate the impact an individual has on the rest of his network. Their electricity consumption is recorded over three months, with the first month serving as the baseline month. After the first month, they are given information on how they can reduce their electricity consumption. No further information is introduced into the group. After the third month the expected energy cost savings are calculated for each household to determine if they had saved up to $10 \%$ of their electricity consumption. The expected energy cost savings calculated use one of the TOU tariffs in South Africa. The 10\% reduction in electricity consumption is due to some daily practices based on category I of energy savings given by the utility company, Eskom, in Trimming (2011). The $10 \%$ criteria is given by Eskom. Examples of activities that would induce savings include changing from incandescent light bulbs to compact fluorescent lamps (CFL), switching off electric water heaters at peak times and switching off appliances when they are not in use etc. The results show that four households out of the 36 actually saved more than $10 \%$ of their electricity cost after two months of performing some energy efficiency measures in their houses. 
The outline of the paper is as follows: section 2 gives a brief background on the TOU tariff. Section 3 discusses the expected energy cost savings mathematical model and section 4 gives the solution methodology. In section 5 a case study to test the model is given and the results are discussed. Section 6 gives the conclusion and suggests further studies.

\section{Background}

Demand side management (DSM) of energy efficiency is a method of curtailing the demand for electricity when the supply is low. Demand side management has to consider the technical, organisational and behavioural solutions that will help decrease energy consumption and demand. The benefits of DSM include the reduction of customer bills, air pollution, heavy investment on power plants and grid congestion as discussed by Saini (2005), Suganthi and Samuel (2012) and Madlener and Myles (2000). The tools used in DSM measures are real time pricing, TOU tariff, smart metering and web-based communication systems Saini (2005). The authors of Plensky and Dietrich (2011) point out that the success of energy efficiency begins with information and insight into the efficiency process involved. This means the more a customer is informed or aware of energy efficiency measures, the more likely the success of that project. The TOU tariff, which is a tool that offers customers different electricity rates at different times of the day, is used in the proposed model to calculate the direct savings of customers.

Because of the increasing rate of electricity demand over the years, Eskom (South African utility company) has introduced a new type of TOU tariff, the Homeflex tariff. This tariff is targeted at residential consumers of electricity. 
In South Africa, the residential sector accounts for $17 \%$ of the total electricity use (kWh) and 30\% of the peak demand (kW) Tariffs (2011). The TOU tariff is designed to be an incentive for customers to reduce their electricity usage during peak periods. The tariff is to be implemented only voluntarily. The energy rates differ according to high-demand (June, July and August) and low-demand seasons, with a higher active charge during the high-demand season. The tariff for the low-demand season (between September and May) consists of the active energy charge (peak period $=0.75 \mathrm{R} / \mathrm{kWh}$, off-peak period $=0.50 \mathrm{R} / \mathrm{kWh}$ ), network access charge $=4.20 \mathrm{R} /$ day, service charge $=3.37 \mathrm{R} /$ day, and environmental levy charge $=0.02 \mathrm{R} / \mathrm{kWh}$, where $\mathrm{R}$ represents the South African rand equivalent to 0.1USD (as at May 2015) Tariffs (2011). The daily peak periods are 08:00 - 10:00 and 18:00 - 20:00 and the off peak periods are 0:00 - 07:00, 11:00, 17:00, and 21:00 - 23:00. Figure 2 gives an illustration of an average daily load profile for one of the households in the study. The load profile gives a general profile illustration of households' electricity consumption per day of an average South African home.

For a day the Homeflex TOU cost is given as

$$
E U=5 E C_{p}+19 E C_{o}+S C+N C+24 E L
$$

where $E U$ is the energy cost per day, $E C_{p}$ is the active energy charge at peak period, $E C_{o}$ is the active energy charge at off peak period, $S C$ is the service charge, $N C$ is the network charge and $E L$ is the environmental level.

Since this new incentive tariff in South Africa is applied on a voluntary basis, it is wise to identify people in a community (network) who will save more energy by using this TOU tariff and spread the news about the advantages of the tariff. This paper identifies the people who will be more likely 


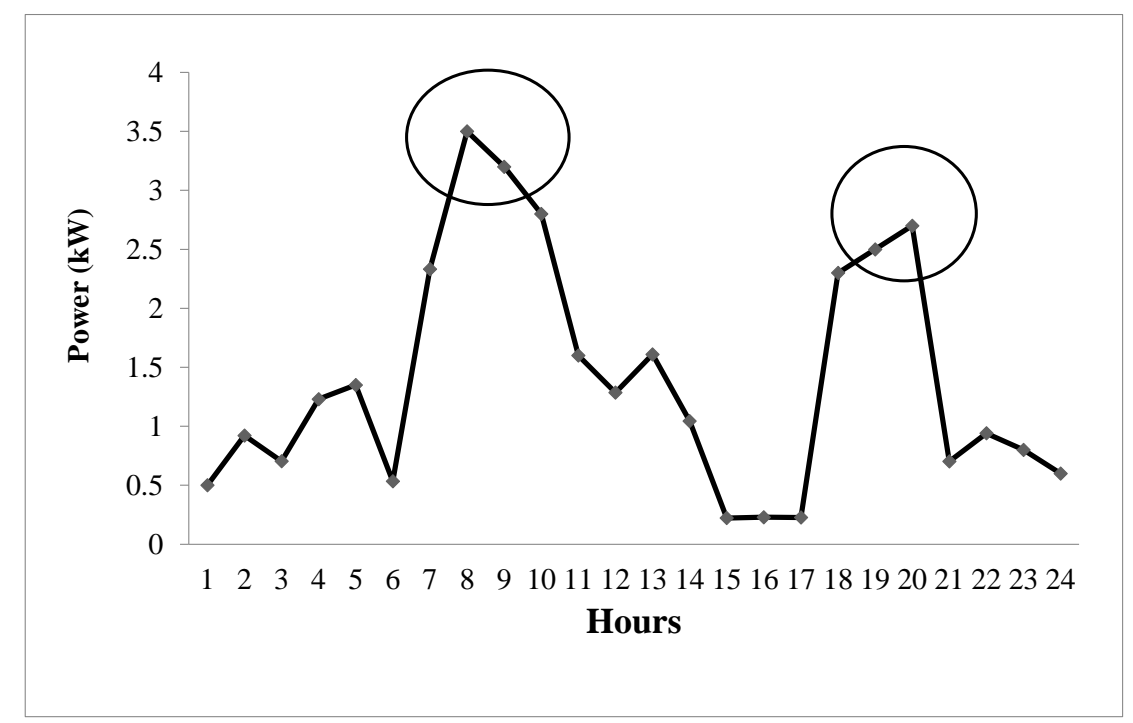

Figure 1: An example of an average 24 hour load profile of a typical household in the network

to accept the new tariff and encourage their neighbours to adopt the tariff, which will enable Eskom to know the people to target in their campaign to promote the Homeflex TOU. This is carried out by showing that interaction of people within their network makes people more aware of energy efficiency and allows room for more savings. The Homeflex TOU tariff is used to calculate the direct savings of the expected energy cost savings model described in section 3 . 


\section{Mathematical model}

In this section, the of the expected energy cost savings mathematical model is formulated. The network is explained, the probabilities and their differences with respect to Ekpenyong et al (2014) are explained and finally the expected energy cost savings is formulated.

\subsection{The network}

A community with $N$ households can be represented by $N$ nodes on a network. The interactions between the nodes are represented by edges on the network. The physical distance between each household is not considered in this paper, however two households are said to be connected when there is a mutual acknowledgement of friendship between them. We consider an undirected network where the path between two nodes is represented with $d_{i, j}=d_{j, i}$ and there is no self connection, that is $d_{i, i}=0$. Within the network, the set of nodes directly connected to $i$ is represented with $M_{i}$. The network topology is represented by an adjacency matrix $B, N^{2}$ matrix with entries; $B_{i, j}=\left\{\begin{array}{ll}1 & , \text { if } i \text { and } j \text { are connected } \\ 0 & \text {, otherwise }\end{array}\right\}$.

For any network the connectivity distribution is the network degree $D$ defined from Newman et al (2002) as $D=\frac{1}{N} \sum_{i=1}^{N} k_{i}$, where $k_{i}=\sum_{j=1}^{N} b_{i, j}$ is the node degree of $i$. The connectivity distribution is used to calculate the functional probability of any node $i$.

\subsection{The probabilities}

The functional probability $p(i, t)$ is the ratio of the node degree $k_{i}$ of $i$ to the connectivity distribution of the network, it is modified from Ekpenyong 
et al (2014) to include the discrete time interval $t=1,2, \ldots, T$. So at every time step $p(i, t)$ is calculated for every node in the network. The functional probability is given as

$$
p(i, t)=\frac{k_{i}(t)}{D(t) N}, \text { for } i=1,2, \ldots, N .
$$

The functional probability in the scope of this study represents the strength of $i$ relative to the entire network, where the functional probabilities for all $i$ 's $\sum_{i=1}^{N} p(i, t)=1$. The functional probability represents the value in terms of information transmission a person has in the network when compared to all people in that network.

The conditional probability $p_{i}(j, t)$ as defined in Ekpenyong et al (2014) and Ekpenyong et al (2013) is the probability that node $i$ is connected to $j$ with at most three nodes between them. In practical terms this refers to the probabilistic quantity of information $i$ can transfer to $j$ when there is at most three nodes between them. It gives a realistic view of the information exchange within a community and highlights the influence $i$ has on his neighbour $j$ with respect to information diffusion of energy efficiency measures. Conditional probability of nodes with five different path lengths $d_{i, j}$ are presented below. The conditional probability in Ekpenyong et al (2014) is modified to incorporate time intervals. The incorporation gives a more accurate description of the influence a person has on his neighbours in comparison to the conditional probability of Ekpenyong et al (2014), where influence is measured on an instance of connection identification of households.

As people grow further from one another the impact of their information transferred is reduced, as shown in Figure 5.1 where the boxes represent the information transferred from the source. As the boxes move further from 
the source the lighter they are, meaning their impact on the receiving node is reduced. The greater the intermediaries between the source node and the receiver of the information, the smaller the information is transferred. In the calculation of $p_{i}(j)$ for a medium sized network, we consider only the case that $j$ is connected to the source node $i$ with degree of connection of at most four. This is a good approximation to the latest research on social networks that an individual is separated from any one in the world by an average characteristic path length $L=4.74$ people ?.

When two nodes are directly connected to each other their path length $d_{i, j}=1$ and the corresponding conditional probability is given as,

$$
p_{i}(j, t):=\frac{1}{k_{i}(t) k_{j}(t)}
$$

This calculates the probability that at time $t$, the influence $i$ has on $j$ with respect to information transmission is a function of the node degrees of both nodes. The reason the inverse of the node degree is used is because the probability that $i$ is connected to $j$ is the inverse of $i$ 's node degree that is $1 / k_{i}$. The same goes for the probability that $j$ is connected to $i$, therefore the conditional probability that $i$ is connected to $j$ is given above when their path length $d_{i, j}=1$.

The conditional probabilities for the different measures of path length $d_{i, j}$ are given below.

For $d_{i, j}=2$

$$
p_{i}(j, t):=\frac{1}{k_{i}(t) k_{j}(t)} \sum_{q \in M_{i}(t) \cap M_{j}(t)} \frac{1}{k_{q}(t)} .
$$


For $d_{i, j}=3$

$$
\begin{gathered}
p_{i}(j, t):=\frac{1}{k_{i}(t) k_{j}(t)} \sum_{(q, r)} \frac{1}{k_{q}(t) k_{r}(t)}, \\
\quad q \in M_{i}(t), r \in M_{j}(t), q \in M_{r}(t) .
\end{gathered}
$$

This means that $r$ and $q$ are directly connected to $i$ and also directly connected $j$. This is a case of $j$ obtaining information from two different sources $(r$ and $q$ ), where $r$ and $q$ obtain their information from one source $i$.

For $d_{i, j}=4$

$$
\begin{aligned}
& p_{i}(j, t):=\frac{1}{k_{i}(t) k_{j}(t)} \sum_{(q, r, s)} \frac{1}{k_{q}(t) k_{r}(t) k_{s}(t)}, \\
& \quad q \in M_{i}(t), \quad r \in M_{q}(t) \cap M_{s}(t), s \in M_{j}(t) .
\end{aligned}
$$

As the number of people between $i$ and $j$ increases the information transferred to $j$ from $i$ becomes insignificant and may even be lost during transmission, therefore for $d_{i, j}=5$,

$$
p_{i}(j, t):=0
$$

The conditional probabilities measure the quantity of information transferred from the end user $i$ to his neighbour $j$. As information is never fully transferred, the more people between $i$ and $j$ the less the quantity of information will be transferred. The condition probability ensures that it represents the fact that all the people who could possibly receive information from the end user do so. In addition, it aids in the calculation of the information entropy that determines the influence a person has on the rest of the network.

The joint probability $p(i, j, t)$ is the probability that the information regarding an energy efficiency project has been transferred from the end user $i$ who performs the project to his neighbour $j$. Inspired by the joint probability of Shannon (1948) $p(i, j, t)$ is given as

$$
p(i, j, t)=p(i, t) p_{i}(j, t)
$$


The joint probability combines the influence a node has on his neighbours and the entire network with regards to information propagation. The functional $p(i, t)$, conditional $p_{i}(j, t)$ and joint $p(i, j, t)$ probabilities are used to calculate the information entropy of node $i$ in the network. The entropy of information theory is defined as the level of information transfer or influence one individual has to the rest of the network. As in Ekpenyong et al (2014) and Shannon (1948) the entropy is defined as,

$$
H(i, t)=-\sum_{1 \leq j \leq N, j \neq i} p(i, j, t) \log _{2} p_{i}(j, t) .
$$

\subsection{The expected energy cost savings model}

The mathematical model calculates the combined direct and indirect savings of energy efficiency measures. Assume the i-th end user is the only person that implements any energy efficiency measure in his/her community, the expected energy cost savings $i$ over a period are calculated as

$$
F_{i}=\sum_{t=1}^{T}\left(S_{i}(t)+\sum_{1 \leq j \leq N, j \neq i} S_{j, i}^{\text {indirect }}(t)\right),
$$

where $S_{i}(t)$ is the direct savings of the $i$-th end user at time $t$ that implements

the energy efficiency measure. $S_{j, i}^{\text {indirect }}(t)$ is the indirect saving in additional to $S_{i}(t)$ because of the energy efficiency information he transmitted to his community. The indirect saving $S_{j, i}^{\text {indirect }}$ from Ekpenyong et al (2014) is given as,

$$
\sum_{1 \leq j \leq N, j \neq i} S_{j, i}^{\text {indirect }}:=H(i) S_{i} .
$$

In order to ensure that people will likely follow an individual's energy efficiency measure, it is important to fashion the indirect savings as a function 
of the direct savings. This means that the total expected energy cost savings of an individual is dependent on his personal effort and his connections in the network. The indirect savings $S_{j, i}^{\text {indirect }}$ gives the savings of the $j$-th end user that is affected by the information transmission of the $i$, where $i$ can be seen as the source of information to the rest of the network. This gives a representation of an end user that performs an energy efficiency measure and is able to transmit that information to others in his/her network.

However, at time $t=t+1, t \neq 0$ the indirect savings of an individual reduces because the value of the information is depreciated, this means people are more likely to forget that they have been told after some time or choose not to implement the energy efficiency measures they heard. As time increases $i$ may choose to interact with the same neighbours or change the people he interacts with about his energy efficiency measures however the potency of his information would have decreased. The decrease of information with respect to time is incorporated into the mathematical model through the indirect savings. Therefore, at time $t=t+1$ the indirect savings is $\sum_{1 \leq j \leq N, j \neq i} S_{j, i}^{\text {indirect }}(t+1)$ is given as,

$$
\begin{aligned}
& \sum_{1 \leq j \leq N, j \neq i} S_{j, i}^{\text {indirect }}(t+1)=\delta H(i, t+1) S_{i}(t+1)-\sum_{1 \leq j \leq N, j \neq i} S_{j, i}^{\text {indirect }}(t), \\
& \text { for } \quad t=1, \ldots T
\end{aligned}
$$

where $\delta$ is the forgetting rate. The forgetting rate enables the depreciation of the effect of information between time $t$ to $t+1$. The forgetting rate is used in advertisement to calculate the information diffusion of adverts over a given time Aravindakshan and Naik (2011), Naik (1999) and West and Harrision (1989). In this study, the information on energy efficiency measures 
can be seen as the advert diffused within the community through social interactions. The forgetting rate borders between 0 and 1 , that is $0<\delta<1$. In literature, the forgetting rate is always close to 1 and expected to be stable and sometimes constant over time Aravindakshan and Naik (2011), Naik (1999) and West and Harrision (1989). For simplicity, the forgetting rate is assumed to be constant for all nodes and is chosen to be 0.9 according to the research conducted by West and Harrision (1989). Equation (12) ensures that the influence of $i$ at $t$ is not included with the influence he has on the network at $t+1$.

The incorporation both the quantity (through entropy $H(i, t)$ ) and quality (through the forgetting rate) of information transferred within the network at every time interval is used to evaluate the indirect savings of an individual and in turn determine the expected energy cost savings.

\section{Solution methodology}

We assume that it is cheaper for neighbours of $i$ to obtain information from $i$ because it is free rather than find information about energy efficiency measures through other means that may cost money and time. The model is solved Java programming language on a 32-bit processor. The reason for using Java is because it can process a large network. The solution methodology is as follows;

Step 1: At time $t=0$ assume that a general external information is available to the whole network and this information is complete without any lost. The information that is referred to in this paper are the different measures one can take to reduce electricity usage in their homes while still enjoying 
similar comfort if they do not perform any energy efficiency measures. Some of these measures are mentioned in Section 5.

Step 2: At $t=1$ obtain the direct savings $S_{i}$, of each node. Calculate the functional $p(i, t)$, conditional $p_{i}(j, t)$ and joint $p(i, j, t)$ probabilities and entropy $H(i, t)$ using equations (2)-(9). Calculate the indirect savings obtained from the entropy and direct savings using equation (10). Calculate the expected energy cost savings for all $i$ as sum of the direct and indirect savings.

Step 3: At $t=t+1, t \neq 0$ calculate the direct savings and indirect savings

$\sum_{1 \leq j \leq N, j \neq i} S_{j, i}^{\text {indirect }}(t+1)$ that is relative to

$\sum_{1 \leq j \leq N, j \neq i} S_{j, i}^{\text {indirect }}(t)$, then calculate the expected energy cost savings of $i$.

Step 4: Continue on Step 3 until $t=T$ then sum to total expected energy cost savings of $i$ for total period.

Step 5: Find the node $i$ with the maximum expected energy cost savings $\max \left(F_{i}\right)$ output solution.

The case study and results for the mathematical model and solution methodology of Section 3 and 4 respectively are given in Section 5 .

\section{Case study and discussion}

\subsection{Case study}

Consider a network of thirty-six people where a rebate is to be given to a limited number of people based on their implementation of energy efficiency measures to reduce the cost of electricity consumption every month. The 
rebates are given to people who have saved $10 \%$ and above of their electricity consumption in response to the information they received from Eskom (the utility company in South Africa) Trimming (2011). The rebate is determined by the total expected energy cost savings of the household. The rebate pricing is not covered in the scope of this work (as it has already been predetermined by the utility company); however this study enables the utility company identify the people are who are more likely to encourage their neighbours to reduce their electricity usage within the community.

Energy consumption data are gathered through a household inventory and actual electricity use during a period of three months in each household.The energy consumption for all 36 households over the three months are given in Table 1.

The first month is a blind baseline measurement, to determine electricity usage before any energy efficiency measure has been taken. Households are educated on simple energy efficiency measures. The simple energy efficiency measures that they implement include changing incandescent bulbs to CFL bulbs, switching off geysers and switching off unused lights etc. The aims of these interventions are to promote energy efficiency awareness, reduce electricity cost and thus reduces electricity usage in the community. The measures are voluntary and there is no penalty for people who do not implement the efficiency measures nor have any savings. In the remaining two months the electricity usage is measured to determine the direct savings. In this case study, the direct savings $S_{i}(t)$ are calculated as a percentage of electricity cost after implementation relative to the electricity cost before implementation. For this study the direct savings for each household is 
calculated as,

$$
S_{i}(t)=\frac{\sum_{c=1}^{30} E U_{b}-\sum_{c=1}^{30} E U_{a}}{\sum_{c=1}^{30} E U_{b}} \times 100
$$

where $c$ represents the time in days, $E U_{a}$ and $E U_{b}$ are the energy cost after and before implementation of energy efficiency measures respectively. The direct savings are calculated in this way because different types of households are used in this study and each saves a different amount of electricity. Comparing the exact amount of electricity saved will not show the true effort of a person's energy efficiency implementation. For illustration purposes, consider two households A and B in the network that implement energy efficiency measures. The first household saves R200 while the second person saves R50. However, before the implementation, household A used to spend R 2500 on its electricity bills while B spent R500. This shows that in actual fact household B saved more, with a $10 \%$ decrease, and household A had only an $8 \%$ decrease in the electricity bill and therefore in electricity consumption. Therefore using a percentage decrease in energy cost depicts the actual results people have achieved in saving. Therefore using percentage decrease in energy cost represents the actual results one has put in to achieve their savings. The assumptions made are,

1. Every individual uses electricity and the savings are based on the average electricity consumption peak periods only, which are from 08:00 to 10:00 and from 18:00 to 20:00 for morning and evening peaks respectively. These peak periods are determined by Eskom (a South African utility company) HomeFlex TOU tariff Tariffs (2011).

2. The calculations and determination of the rebates are not in the scope 
of this paper.

3. The criteria for giving the subsidy are based on the percentage of energy cost saved and how much influence each individual has in the community.

4. The rebate is given to a household that has saved at least $10 \%$ of energy cost after two months. The energy cost savings are based on the morning and evening electricity consumption peak and off-peak periods given by the Homeflex TOU tariff.

5. The network is undirected.

The relationships among members of a network is used to establish a social network graph. In this paper the relationship is based on mutual acknowledgement of friendships among households in the network. The network graph is constructed from nodes (households) and edges (relationships). Household $i$ and $j$ must agree that they know each other and are friends be-

fore a link (edge) is made between them. How each friendship is formed and the level of friendship such as close, very close and acquaintances are not covered in the scope of this paper. The network graphs of Figure 2 and 3 are based on the adjacency matrix of the 36 members of the community. The graph is an unweighted and undirected graph, that is when two households are connected $d_{i, j}=d_{j, i}=1$. The network graphs showing the connections among households in a community after information about energy efficiency is introduced into the network is given in Figure 2 and 3.

\subsection{Results and discussion}

The network graph of Figure 2 and 3 is built using the connections of households. Similar to Ekpenyong et al (2014), the graphs are unweighted 


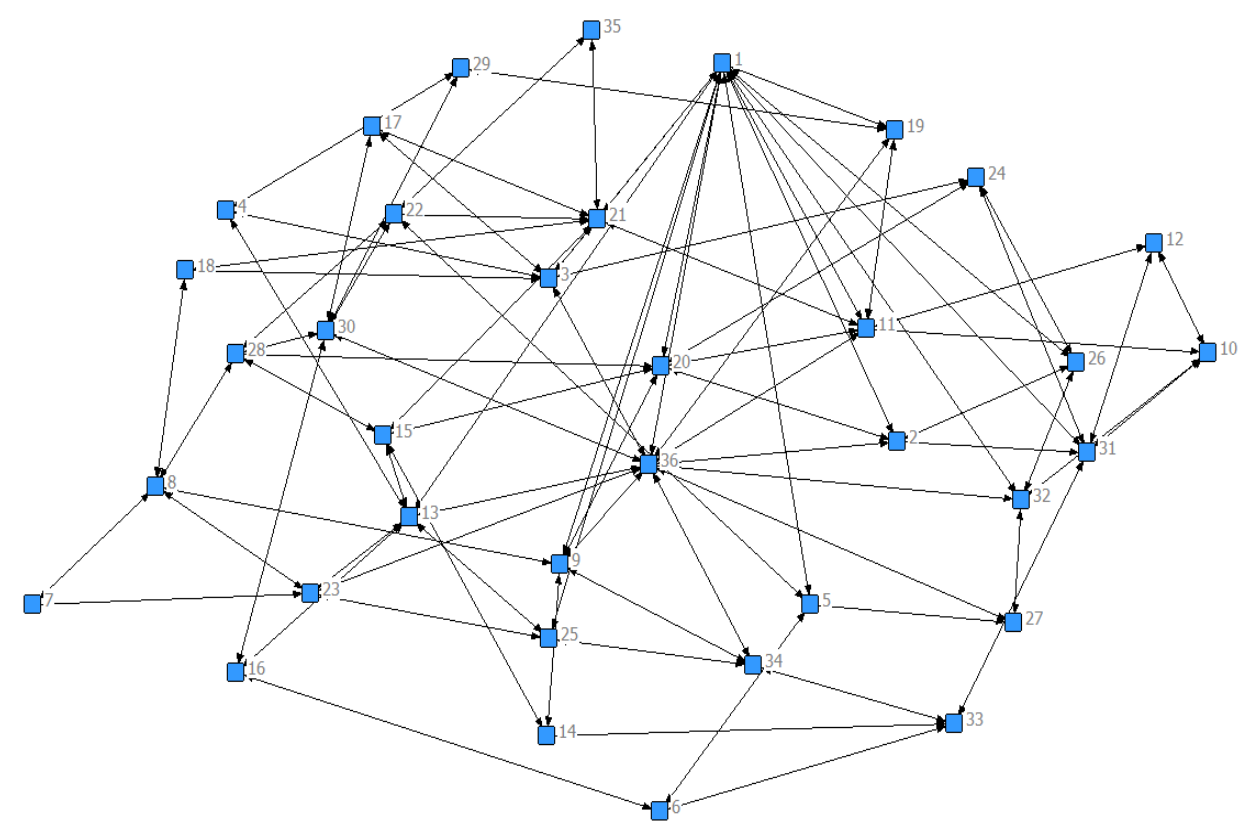

Figure 2: First month network graph

and undirected graphs, that is when two households are connected $d_{i, j}=$ $d_{j, i}=1$. The average number of nodes that any node $i$ is connected, which is the network degree $D$ is 3 .

The percentages of the total expected energy cost savings are given in figure 4 . Figure 4 shows the percentage savings for the two months (i.e. $\mathrm{T}=$ 2) after energy efficiency measures have been implemented in each household. The results show that household 5 has the highest percentage of expected energy cost savings; however, the savings of the second month are higher than the savings of the first month. The increase in savings is due to the personal effort of the individual (direct savings), the increase in the node degree of that individual and the type of connections. The reward for the information-sharing among members of the network through indirect savings 


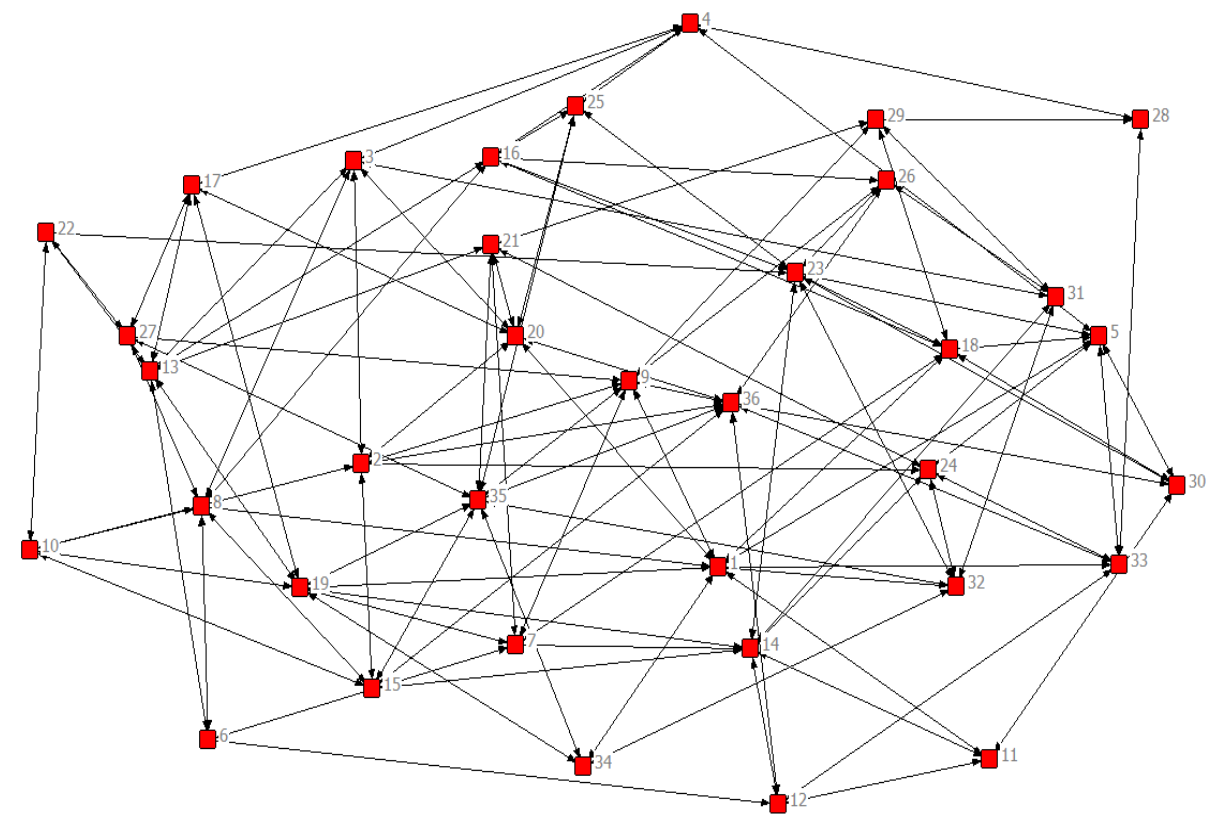

Figure 3: Second month network graph

encourages them to save more and thus increases awareness of energy efficiency in the community. It can be seen that household 5 interacted with four people about energy efficiency measures after the first month and seven people after the second month. The increase in interaction of people enables the households to spread information and in so doing, awareness of energy efficiency is increased. The households with the highest percentage of savings are household 5 with 30\% savings, followed by households 17, 2 and 11 with percentage savings of $15.1 \%, 14 \%$ and $10.7 \%$ respectively. The results show that in the 36-member network, only four households had expected energy savings of above $10 \%$. They not only endeavoured to reduce their energy consumption but they also transmitted information about their energy efficiency measures to the rest of the network. 


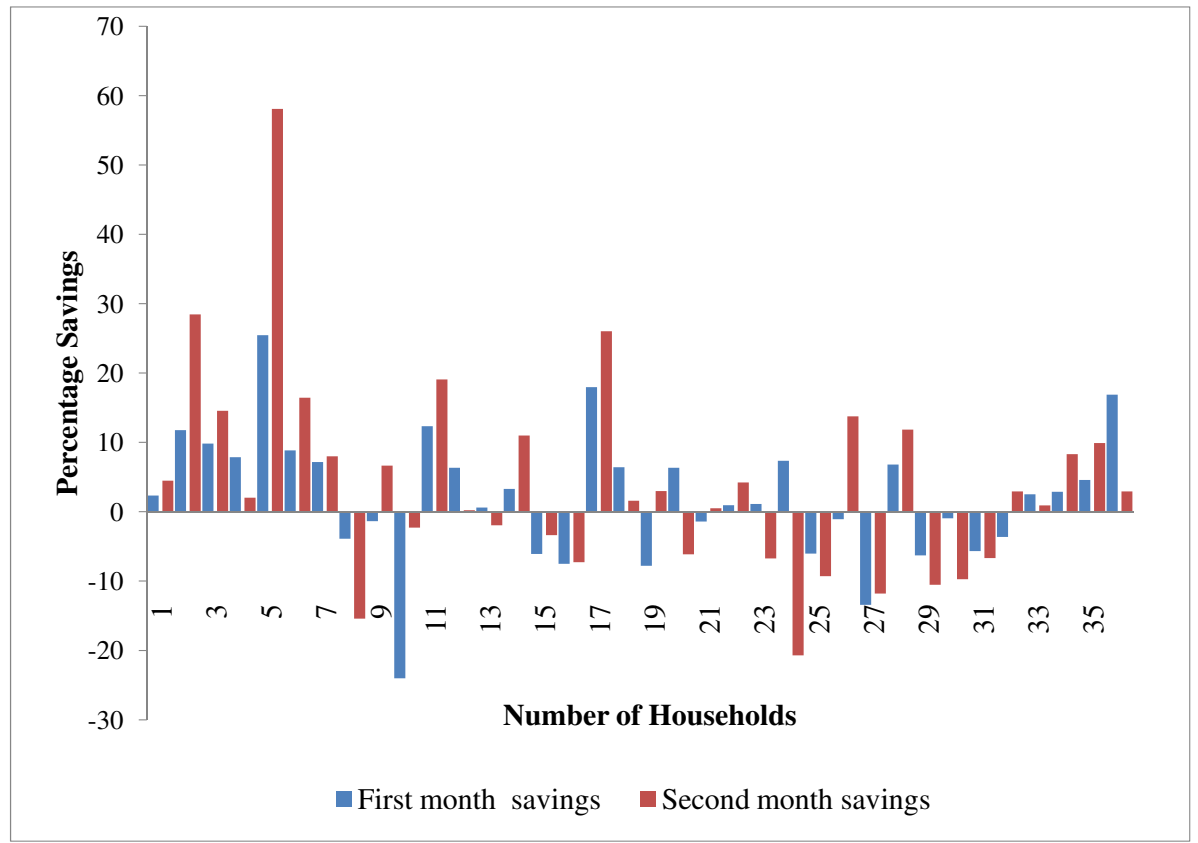

Figure 4: Percentage of energy cost savings for each household after two months

These results show that savings depend not only on a personal effort of an individual, but also on the connections and his influence on his neighbours to transmit information about energy efficiency. For example, household 2 has only seven connections after the second month, as can be seen in Figure 3. However his neighbours (households 3, 15, 8, 24, 20 and 36) have higher node degrees $k_{i}$ because of this household 2 is able to obtain a high level of influence when calculating the indirect savings of household 2 that are used to evaluate the total expected energy cost savings. This model acknowledges the hard work of individuals to save energy, as well as the ability of that individual to transfer the information to the rest of the network based on his influence in the community. The negative percentages for households in Figure 4 are due to an increase in electricity consumption of households 
after the baseline is obtained. This may be due to a number of reasons, particularly the rebound effect. However, it is not covered in the scope of this study.

This case study is intended to illustrate the usefulness of the expected energy cost savings model in identifying people who influence their community by propagating information about energy efficiency. The model captures the personal effort of the individuals (direct savings) and also their social effort (indirect savings) in the reduction of their energy usage. This will in turn help reduce the energy consumption of the entire community and in a wider scope the energy production by the utility company. This model is useful for providing information to members of community about their energy usage, who is making the most impact through information transmission and the people who have been influenced. Such information can trigger more effort from the community members to be more energy efficiency concious.

The results give a real life case scenario and shows that although some people do not save even though they have been informed about the energy efficiency measures, more than $50 \%$ of the people in the network show significant savings. This goes to show that human interaction can indeed help in the reduction of energy usage and thus instigate energy cost savings for that individual without any extra cost to the utility company. This type of research arms the end users with information about energy efficiency measures as such, informed decisions can be made on how he/she utilises their electricity. And if the individual is willing to reduce his/her electricity consumption then, the utility company also wins by reduction of electricity demand at no cost to them through different means of transmitting such information such 
as, television, radio, social media etc.

\section{Conclusion and further studies}

Expected energy cost savings of any energy efficiency project are divided into two parts, namely direct and indirect energy saving. An expected energy cost savings mathematical model that factors in the reduction of information propagated over time in a network is formulated. The mathematical model is tested on a 36-household community. The results show that the increase in connections among members of the network enhances the potential for an increase in energy cost savings over time. The results also show that the indirect savings actually increase the total expected energy cost savings of an individual. This can be one of the ways to broadcast the advantages of energy efficiency in any network. When individuals see how much their information about energy efficiency has enabled them to increase their savings, the information is spread faster. Further studies on the social impact of energy efficiency will focus on how the different levels of relationships and media are used to propagate energy efficiency measures that will influence savings in the social network.

\section{Acknowledgements}

This research is supported by the National Hub for the postgraduate programme in Energy Efficiency and Demand Side Management at the University of Pretoria, South Africa. 


\section{References}

Aravindakshan, A. Naik, P. A. (2011) How does awareness evolve when advertising stops? Marketing Letters, 22: pp. 315-326.

Chen, J Taylor J. E. Wei, H. (2012) Modeling building occupant network energy consumption decision making: the interplay between network structure and conservation. Energy and Buildings, 84: pp. 344-351.

Croucher, M. (2011) Potential problems and limitations of energy conservation and energy efficiency. Energy Policy, 39: pp. 5795-5799.

Ekpenyong, U. E. Zhang, J. Xia, X. (2014) Mathematical Modelling for the Social Impact to Energy Efficiency Savings. Energy and Buildings, 47: pp. $515-524$

Ekpenyong, U. E. Zhang, J. Xia, X. (2013) Social impact of energy efficiency savings based on time of use tariff. Proceedings of International Conference on Applied Energy, Pretoria, South Africa (July).

International Performance Measurement and Verification Protocol, EVO 10000-1. (2007) Energy Valuation Organisation.

Jaina, R. K. Gulbinasb, R. Taylor, J E. Culligan, P. J. (2013) Can social influence drive energy savings? Detecting the impact of social influence on the energy consumption behavior of networked users exposed to normative eco-feedback. Energy and Buildings, 66: pp. 119-127.

King, S. P. (1995) Search with free riders. Journal of Economic, Behaviour and Organization, 26: pp. 253-271. 
Madlener, R. Myles, H. (2012) Modeling socio-economic aspects of bioenergy systems: a survey prepared for IEA bioenergy task 29". IEA Bioenergy Task 29 Workshop. Brighton/UK (July).

Milgram, S. (1967) The small world problem. Psychology Today, 1: pp. 61-67.

Naik, P. A. (1999) Estimating the half life of advertisement. Marketing Letters, 10: pp. 351-362.

Newman, M. E. J Watts, D. J. Strogatz, S. H. (2002) Random graphs model for social networks. Proceedings of the National Academy of Sciences, 99: pp. 2566-2572.

Peschiera, G. Taylor, J. E. (2012) The impact of peer network position on electricity consumption in building occupant networks utilizing energy feedback systems. Energy and Buildings, 49: pp. 584-590.

Palensky, A. Dietrich, P. D. Demand side management, demand response, intelligent systems and smart loads. IEEE Transaction on Industrial Informatics, 7: pp. 381-388.

Saini, S. (2005) Conservation vs. generation: the significance of demand side management (DSM), its tools and techniques. Refocus.

Shannon, C. E. (1948) A mathematical theory of communication. The Bell Technical Journal, 27: pp. 376-423, 623-656.

Suganthi, L. Samuel, A, A. (2012) Energy models for demand forecasting. Renewable and Sustainable Energy Reviews, 6: pp. 1223-1240. 
Tariffs 86 Charges Booklet 2011/2012 (2011), Eskom.

Trimming $10 \%$ is easier than you think [Internet] (2011). Eskom Integrated Demand Management, [cited 2015 January 10]. Available from: http://www.eskom.co.za/sites/IDM/Documents.

Wassaerman, S. Faust, K. (1999)Social network analysis in the social and behavioural sciences. Social Network Analysis: Methods and Applications. Cambridge: Cambridge University Press.

Watts, D. J. Strogatz, S. H. (1998) Collective dynamics of 'small - world' network. Nature, 393: pp. 440-442.

Weinstein, R. Scott, R. Jones, C. (1989) Measurement of "free-riders" in energy conservation programs. Evaluation and Program Planning, 12: pp. 121-130.

West, M. Harrison, B. (1989) Bayesian forecasting and dynamic models. New York: Springer-Verlag.

Xu, X. Taylor, J. E. Pisello, A. L. Culligan, P. J. (2012) The impact of place-based affiliation network on energy conservation: an holistic model that integrates the influence of buildings, residents and the neighborhood context. Energy and Buildings, 55: pp 637-646. 
Table 1: Average monthly energy consumption (kWh) of 36 households

\begin{tabular}{llll}
\hline Household & Month 1 & Month 2 & Month 3 \\
\hline 1 & 16467.7 & 16094.8 & 15748.1 \\
2 & 34764.3 & 30790 & 26070.5 \\
3 & 27740.7 & 25091.2 & 24077 \\
4 & 24331.8 & 22460.1 & 23840.2 \\
5 & 20862.2 & 15674.9 & 11818.2 \\
6 & 24812.2 & 22657.4 & 21110.2 \\
7 & 14152.4 & 13157.3 & 13101.2 \\
8 & 19720 & 20469.4 & 22833.1 \\
9 & 12990.3 & 13162.8 & 12137.4 \\
10 & 30781.2 & 37989.2 & 31817.7 \\
11 & 24133.3 & 21247.4 & 20063.6 \\
12 & 13761.4 & 12908.3 & 13712.5 \\
13 & 11170.3 & 11105.9 & 11380.7 \\
14 & 16108.1 & 15590.5 & 14417.2 \\
15 & 8347.1 & 8841.6 & 8653.3 \\
16 & 25495 & 27368.5 & 27490.2 \\
17 & 29843.4 & 24615.2 & 23426.6 \\
18 & 8958.9 & 8398.7 & 8815.6 \\
19 & 11037.2 & 11875.1 & 10712.5 \\
20 & 21606.5 & 20275.3 & 22787.3 \\
21 & 9821.4 & 9955.5 & 9775.9 \\
22 & 15233.6 & 15094.4 & 14603.9 \\
23 & 18946.4 & 18741.5 & 20176.7 \\
24 & 12204.6 & 11332.1 & 14482 \\
25 & 8784.2 & 9299.7 & 9645 \\
26 & 14981 & 15139.4 & 12944.4 \\
27 & 7388.7 & 8356.6 & 8378.6 \\
28 & 30971 & 28924 & 27543 \\
29 & 15578.8 & 16536.2 & 17310.3 \\
30 & 8241.3 & 8316.3 & 9036.6 \\
31 & 11732 & 12378.4 & 12561.6 \\
32 & 10067.9 & 10422.9 & 9777.9 \\
33 & 16971.7 & 16554.2 & 16814.9 \\
34 & 24359.3 & 23677 & 22408.4 \\
35 & 24857.8 & 23743.3 & 22533.3 \\
36 & 23915.328 & 20012 & 23211.4 \\
\hline & & & \\
\hline & 15 &
\end{tabular}

